\title{
Integrating Flash Cards with Narratives for Mobile Learning of English Vocabulary
}

\author{
https://doi.org/10.3991/ijim.v14i04.11723 \\ Chien-Hung Lai ${ }^{(凶)}$, Bin-Shyan Jong, Yen-Teh Hsia, Tsong-Wuu Lin \\ Chung Yuan Christian University, Taoyuan City, Taiwan \\ soulwindecycu.org.tw
}

\begin{abstract}
The world has seen a rapid development in mobile devices in recent years. Mobile devices have the advantage of immediacy and convenience. Their uses are not restricted to desktops and classrooms. Many assisted learning systems run on mobile devices. These systems give students the opportunity to learn anytime and anywhere. Language learning is one of the key research issues underlying the development of such systems. There are many ways to use mobile devices to teaching English. This includes the use of pictured flash card to learn English vocabulary, a teaching approach that has been shown to be effective. In the current research, an assisted learning system was developed for learning English vocabulary. It combines pictured flash cards with stories. The goal was to see whether the addition of stories to pictured flash cards for learning English vocabulary could have a significant effect on learning motivation, learning achievement, and anxiety. As the result of an associated educational experiment showed, students generally agreed with the use of such a system to help them learn English vocabulary, and they also made use of leisure time to learn. Compared to students using "plain" pictured flash card for learning, students using pictured flash cards with stories had a significantly lower level of anxiety, and they also learn better as far as learning motivation and achievement were concerned.
\end{abstract}

Keywords - Flash Card, story-based, pictured flash card, learning motivation, learning achievement, anxiety in learning English

\section{Introduction}

The learning of vocabulary is very important for learners of the English language [18]. Wilkins points out that while people with a lack of grammatical knowledge could only express fragments of what they want to convey, they would not be able to express anything at all if they don't have the vocabulary they need [17]. Fauziati also mentions that without an adequate vocabulary, people will have problems expressing their thoughts, whether orally or in writing [3]. The amount of vocabulary one has plays an important role in how the person is able to communicate with others. Therefore, it is important for foreigners who try to make English their second language to have a tool that can effectively help them with the learning of English vocabulary. 
As the Internet and mobile phone technology develop, the form of learning has gradually transformed into a multi-facet format, including learning in the classroom, learning on the Internet, and ubiquitous learning. On the one hand, there is e-learning, which does not require the instructor and the students to meet face to face. On the other hand, there is also m-learning (mobile learning) in which students can learn anytime and anywhere. The convenience and versatility offered by mobile devices make it possible for researchers to conduct research on various topics related to m-learning. For example, Shin uses PDA to guide students in their outdoor learning activities. When a student is in one of the designated areas of a temple, the student can learn stories of that part of the temple as well as characteristics of its architecture by browsing Web pages on the PDA [16]. Hwang attached RFID tags to lab instruments. When students encounter problems in using a lab instrument, they can obtain operational information by sensing the RFID attached to the instrument [7]. As another example, Mitchell and Nicholas [10] developed a system that is capable of helping students learn about plantations in an outdoor environment. By using their cell phones to take shots of the visual code that was placed alongside of a plant, students learn about the plant by obtaining information from the Web. As for the learning of English, there were also quite a few m-learning related research. Cui and Bull [1], for example, use mobile devices to help Chinese students learn English vocabulary under different circumstances. Gromik [4] asked students to record their own speeches on assigned topics and then upload these speeches. Through this recording process, students improved on their oral abilities.

Many learning technology researches integrate particular teaching strategies with learning materials and put the resulting systems on learning platforms that are easily accessible by students via the use of mobile devices and/or personal computers. This requires the use of a suitable teaching strategy. There are many teaching strategies an instructor can use. One popular strategy is to use flash cards to assist the memorization of vocabulary of a foreign language [11]. More recently, Huang [6] integrated learning materials into a game and used GPS storytelling to guide students to pre-designated learning spots, and McGraw, Yoshimoto, and Seneff [9] built an interactive card game to allow the students learn English vocabulary by playing games.

One criticism of the use of flash cards for vocabulary learning is that there is a lack of linguistic context [12]. To improve on this aspect, the following teaching strategy was developed for the current study. First, flash cards accessible via the use of mobile devices were used to help students memorize vocabulary that appeared in news or stories. Two, the news or story in question was shown to the students before they start to use the flash cards for learning related vocabulary. To also improve on the aspect of learning words describing abstract concepts, flash cards relating exemplary sentences and pictures were used in this research. By developing an App that runs on Android-based cell phones, students were able to use the system for learning vocabulary anytime and anywhere. The purpose of this research was to verify the following three hypotheses: 
- Story-based flash cards are more effective than traditional (decontextualized) flash cards for increasing learning motivation with regard to learning English as a second language.

- Story-based flash cards are more effective than traditional (decontextualized) flash cards for increasing learning achievement with regard to learning English as a second language.

- Flash-card based vocabulary learning is effective for reducing learning anxiety with regard to learning English as a second language.

\section{$2 \quad$ Words716 - A System That Assists the Learning of English Vocabulary}

In a contemporary society, the importance of English as a foreign language is undeniable. To learn English as a foreign language, the mastering of vocabulary is essential [8]. If there is not enough vocabulary, one may misunderstand what an article says or even find that article incomprehensible [14]. It is for this reason the learning of English vocabulary was chosen to be the subject of experimentation in this research. In order that the subjects could very easily participate in the experiment, it was decided to develop an App, so that the subjects could use smart phones to access the experimentation platform anytime and anywhere. Vocabulary tested in GEPT (General English Proficiency Test) was used as a basis for choosing the vocabulary to learn. Digitized, pictorial flash cards, which were accompanied by stories, constitute the major component of this App named Words716. Figure 1 shows the main page of Word716, which is what learners first see when they use Words716 to learn English vocabulary. There are four choices on the main page: story mode, word list, exercise, and portfolio. Learners make their choices depending on their personal preferences.

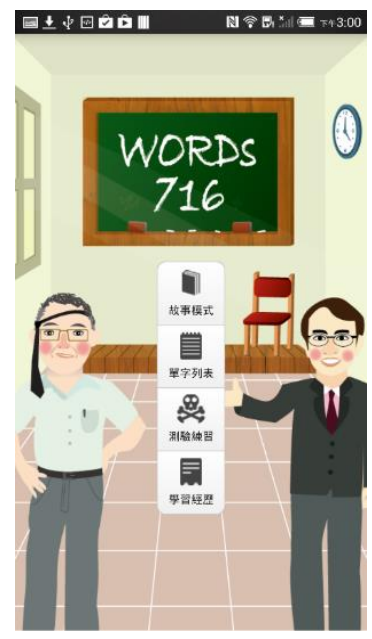

Fig. 1. Main page of Words 716 


\subsection{Story mode}

Figure 2 shows what the learner encounters right after he/she selects "Story mode" in the main page. There will be stories for the students to read, and the students can select what they want to read (the screen snapshot on the left of Figure 2). In the middle of Figure 2, the learner has selected a story entitled KANO. The learner can scroll up and down using the mouse. If the learner clicks a word that is colored blue, a corresponding flash card (the screen snapshot on the right of Figure 2) will appear. This card contains a Chinese translation of the word, a sentence illustrating the use of this word, and a Chinese translation of the exemplary sentence.
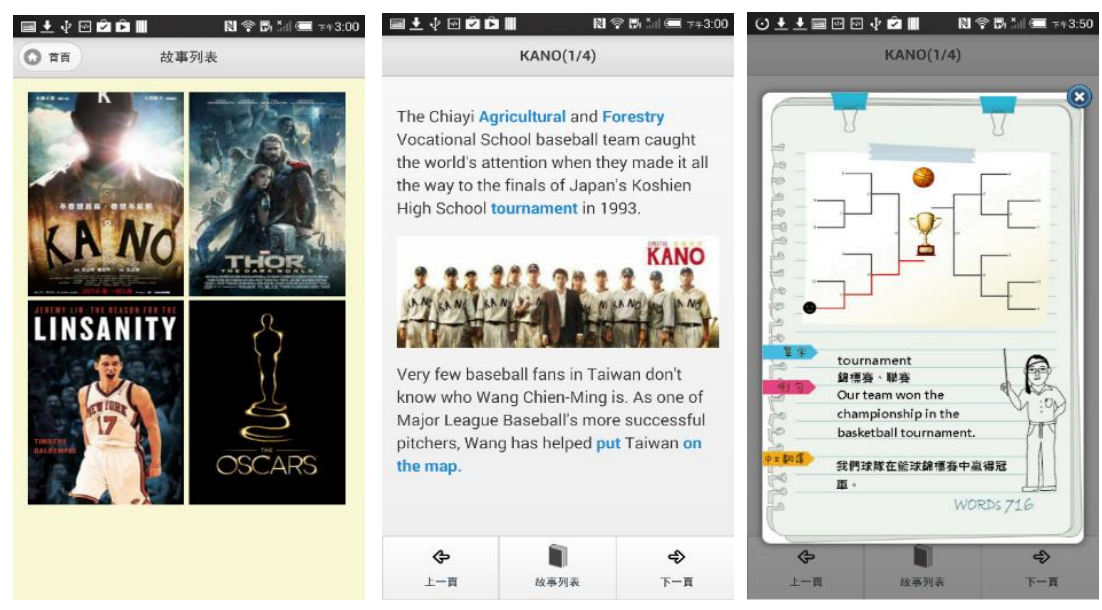

Fig. 2. Interface of story mode

\subsection{Vocabulary listing}

Words716 also provides a listing of the vocabulary for each story. The learner first selects "Listing of vocabulary" in the main page (Figure 1) and then selects the name of a story. A listing of the vocabulary of the story then appears (the screen snapshot on the left of Figure 3). When the learner selects a word in the list, a corresponding flash card appears (the snapshot on the right of Figure 3). When the meaning of a word such as "energize" is abstract and is difficult to be directly shown as a picture, the system shows a picture that corresponds the exemplary sentence instead. For example, the picture shown in the screen snapshot located on the right of Figure 3 is intended to correspond to the exemplary sentence "The cheer leaders' dance energizes the basketball players." 

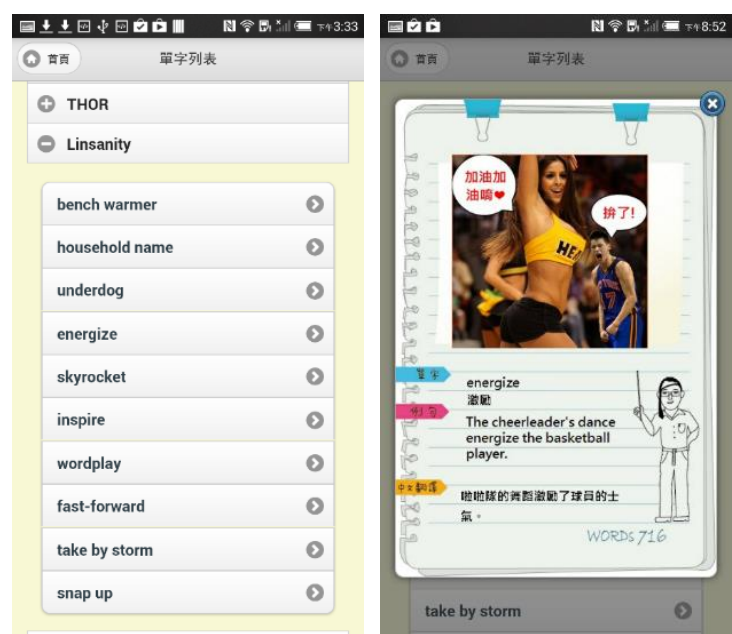

Fig. 3. Interface of vocabulary listing

\subsection{Practices for the test}

When students think that they have finished a learning stage, they can use the practice functionality of the system to check what they have learned. By first selecting "Practices for the test" in the main page (Figure 1) and then clicking the OK button of a notification for practice, the practice begins (Figure 4). For each question, the learner selects an answer and clicks the OK button. If the learner's answer is correct, the next question appears. If the learner's answer is incorrect, the system will only say that the answer is incorrect and will not tell the learner what the correct answer is; the purpose here is to let the learner really acquire the needed vocabulary by going thru flash card learning.

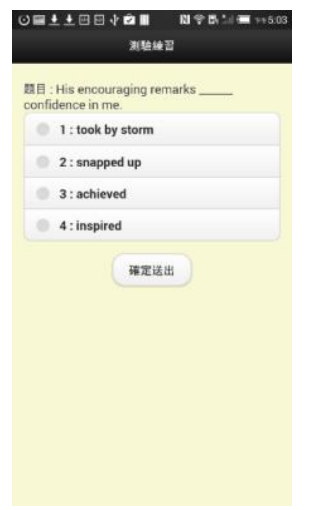

Fig. 4. Interface of practice for tests 


\subsection{Learning portfolios}

In order for the learners to know how they are doing; the system keeps track of the results of practices for all learners. After a learner selects "Learning portfolio" in the main page (Figure 1), the system presents to the learner his/her percentage of correct answers for each story. By knowing where his/her weakness is, the learner can then go back to the story (or stories) for which he/she has not acquired enough vocabulary to redo flash card learning.

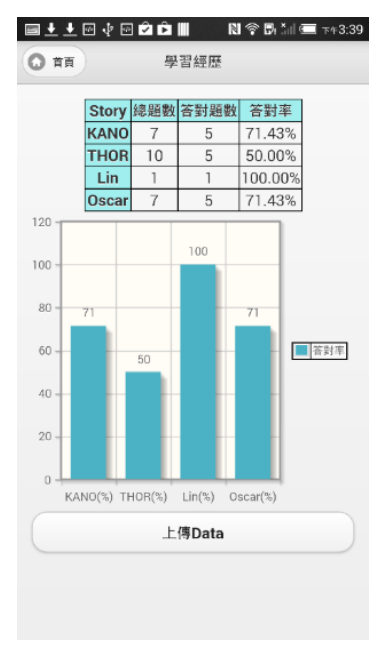

Fig. 5. Interface of learning portfolio

\section{$3 \quad$ Methods}

\subsection{Experiment design}

Participants of this experiment were sophomores of Chung Yuan Christian University who were taking "Practical English II". These sophomores were all majoring in Information and Computer Engineering. Words716 was developed for Android-based smart phones. Therefore, the experimental group consisted of 38 students of one class who had Android-based smart phones, while the control group consisted of 20 students of another class who had Android-based smart phones. Since the effectiveness of the use of flash cards in mobile learning has already been demonstrated [2], both groups of this experiment used digitized flash cards for vocabulary learning. The only difference was that the experimental group had stories relating the flash cards, while the control group did not have any story relating the flash cards.

The experiment lasted for two weeks. Before the experiment, students of both groups filled out a questionnaire about their learning motivation and learning anxiety. This is then followed by two weeks' use of Word716. Students who had smart phones 
could use Words716 to do vocabulary learning in their leisure time. Students who did not have smart phones could use their personal computers to access the Web page version of Word716 to do vocabulary learning. Students could also check their own progresses at any time by consulting their learning portfolios. After the two weeks' use of Word716 was over, the students again filled out the same questionnaire, and they also went through a posttest. When the students filled out the second questionnaire, they were also asked of some additional questions about system use.

\subsection{Questionnaire}

The purpose of this research was to understand how learning motivations, learning achievements, and anxiety in learning English may be affected when students used different systems to do vocabulary learning. There were mainly two parts in the questionnaire. The first part came from Motivated Strategies for Learning Questionnaire (MSLQ) [13]. After excluding the part of MSLQ that deal with emotions, twenty-six items remained and were included in the questionnaire. The second part was what Horwitz, Horwitz, and Cope [5] used to measure anxiety in learning English. All thirty-three items of this questionnaire were included in the current questionnaire. A five-point Likert scale was used for answering all items. In the questionnaire, there were also some additional questions asking how the subjects felt about system use, so as to collect the opinions of the subjects as well as their feedback.

\section{$4 \quad$ Results}

The learning assistance system (Words716) used in this research integrates stories with flash card learning of English vocabulary. With the convenience offered by mobile devices, students were able to do vocabulary learning via the use of digitized flash cards anytime and anywhere. As expected, results of the pretest questionnaire showed that there was no significant difference between the control group and the experimental group, whether in learning motivation, learning achievements, or anxiety in learning English. Below are discussions of how the two groups differ in these aspects after using Words716 for learning English vocabulary.

\subsection{Learning motivation}

Even though the learning motivation of both groups increased in the posttest, there were still no significant differences between the learning motivations, as shown by the ANOVA test results $(\mathrm{F}(1,56)=0.027, \mathrm{p}>0.05)$. However, a closer examination reveals that the learning motivation of the experiment group increased significantly $(\mathrm{F}(1,74)=$ $4.060, \mathrm{p}<0.05)$, whereas the learning motivation of the control group did not $(\mathrm{F}(1,38)$ $=0.932, \mathrm{p}>0.05)$. In other words, the addition of stories to flash card-based vocabulary learning is effective in increasing learning motivation. Therefore, Hypothesis 1 (that story-based flash cards are more effective than decontextualized flash cards for in- 
creasing learning motivation with regard to learning English as a second language) is accepted in this experiment.

Table 1. ANOVA results for learning motivation

\begin{tabular}{|l|l|l|l|c|c|c|}
\hline \multicolumn{1}{|c|}{ Group } & \multicolumn{1}{|c|}{ Test } & N & Mean & SD & $\boldsymbol{F}$ & $\boldsymbol{P}$ \\
\hline \multirow{2}{*}{ Experimental } & Pretest & 38 & 112.131 & 22.819 & 4.060 & 0.048 \\
\cline { 2 - 7 } & Posttest & 38 & 121.421 & 16.941 & & \\
\hline \multirow{2}{*}{ Control } & Pretest & 20 & 115.35 & 20.643 & 0.932 & 0.340 \\
\cline { 2 - 7 } & Posttest & 20 & 120.7 & 13.707 & & \\
\hline
\end{tabular}

\subsection{Learning achievement}

Table 2 presents the results of ANOVA test of the students' learning achievements. From Table 2, it can be seen that there is a significant difference in learning achievements between the experimental group and the control group. This suggests that the integration of stories into flash card-base vocabulary learning is effective in increasing leaning achievements. In addition, from statistics of system use in Table 3, it can be seen that students in the experimental group were more willing to use Words716 for vocabulary learning. Although the number of students in the experiment group (38) was greater than the number of students in the control group (20), the average number of clicking of the experimental group (37.8) was still higher than that of the control group (31.2). In other words, the integration of stories into flash card learning of vocabulary had caused students to be more interested in using the system, which, in turn, had caused them to be more familiar with the vocabulary they were supposed to acquire, thereby causing them to gain a higher score in the posttest. Therefore, Hypothesis 2 (that story-based flash cards are more effective than decontextualized flash cards for increasing learning achievement with regard to learning English as a second language) is also accepted in this experiment.

Table 2. ANOVA results for learning achievement

\begin{tabular}{|c|l|c|c|c|c|c|}
\hline \multicolumn{1}{|c|}{ Test } & \multicolumn{1}{|c|}{ Group } & N & Mean & SD & F & $\boldsymbol{p}$ \\
\hline \multirow{2}{*}{ Pretest } & Experimental & 38 & 65.473 & 14.329 & 0.126 & 0.724 \\
\cline { 2 - 7 } & Control & 20 & 64 & 16.364 & & \\
\hline \multirow{2}{*}{ Posttest } & Experimental & 38 & 76.736 & 17.169 & 4.120 & 0.047 \\
\cline { 2 - 6 } & Control & 20 & 67 & 17.74 & & \\
\hline
\end{tabular}

Table 3. Total number of clicking for each group

\begin{tabular}{|l|c|c|}
\hline & Experimental & Control \\
\hline Number of clicking & 1438 & 623 \\
\hline
\end{tabular}

\subsection{English language anxiety}

For both the control group and the experimental group, anxiety in learning English decreased after using Words716. Even though there were no significant differences 
between the two groups $(F(1,56)=1.139, p>0.05)$, anxiety in learning English did decrease significantly for both groups $(F(1,74)=21.585, p<0.05$ for the experimental group; $F(1,38)=6.229, p<0.05$ for the control group). In other words, the use of Words716 for flash card-based vocabulary learning was effective in decreasing anxiety in learning English. Therefore, Hypothesis 3 (that flash-card based vocabulary learning is effective for reducing anxiety in learning English as a second language) is accepted in this experiment.

Table 4. ANOVA results for anxiety in learning English

\begin{tabular}{|l|l|c|c|c|c|c|}
\hline \multicolumn{1}{|c|}{ Group } & \multicolumn{1}{|c|}{ Tests } & N & Mean & SD & $\boldsymbol{F}$ & $\boldsymbol{p}$ \\
\hline \multirow{2}{*}{ Experimental } & Pretest & 38 & 103.394 & 13.407 & 21.585 & 0.000 \\
\cline { 2 - 6 } & Posttest & 38 & 88.263 & 14.944 & & \\
\hline \multirow{2}{*}{ Control } & Pretest & 20 & 109.5 & 20.73 & \multirow{2}{*}{6.229} & 0.017 \\
\cline { 2 - 5 } & Posttest & 20 & 94.45 & 17.248 & & \\
\hline
\end{tabular}

Even though anxiety in learning English significantly decreased for both the control group and the experimental group, learning motivations did not significantly increase for both groups. Therefore, a Pearson correlation test was made between anxiety in learning English and learning motivation to see whether there was a relation between the two. Figures 6 and 7 present the results of Pearson correlation tests. It was found that for the experimental group, (decrease in) anxiety in learning English was strongly correlated with (increase in) learning motivation. But for the control group, the correlation was not strong. This means that the integration of stories into flash card-based vocabulary learning helps to link anxiety in learning English and motivations for learning English together. By using such a system to learn English vocabulary, students gain two benefits simultaneously. On one hand, they have a significantly stronger motivation to learn. On the other hand, they also have significantly less anxiety in learning.

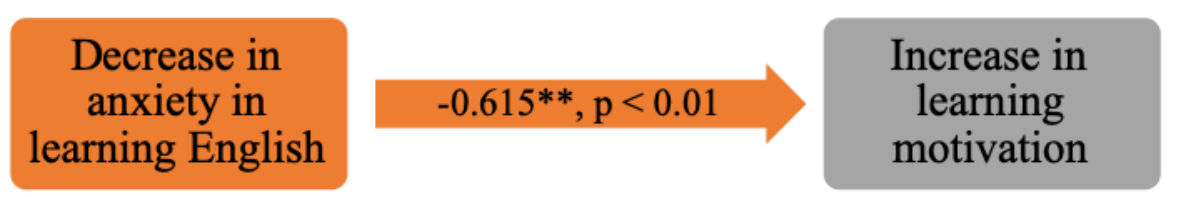

Fig. 6. Pearson correlation coefficient - relation between anxiety in learning English and learning motivation (the experimental group)

\section{Decrease in
anxiety in
learning English}

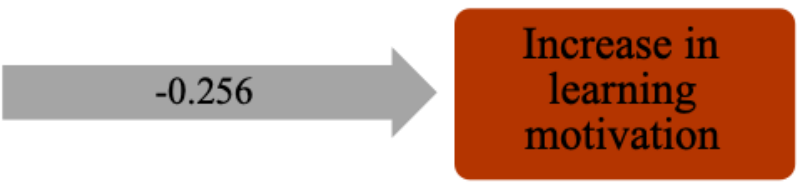

Fig. 7. Pearson correlation coefficient - relation between anxiety in learning English and learning motivation (the control group) 


\subsection{Questionnaire - System use and user feedbacks}

To understand how users felt about the system and also to get user feedbacks, a questionnaire was conducted. There were 11 items in the questionnaire (Table 5). A 5-point Likert scale was used for answering Item No. 1 through Item No. 9. A 10-point Likert scale was used for answering Item-10. The last item asked about what the user felt about Words716. A reliability analysis was done on the questionnaire results, and Cronbach's $\alpha$ was found to 0.930 (> 0.7). Therefore, the results of the questionnaire were trustworthy.

The first and second items asked whether the students were able to make use of the conveniences offered by mobile devices to learn anytime and anywhere. Students of both groups agreed that the use of smart phones to access Words716 offered the convenience of learning anytime and anywhere. The third, fourth, and fifth items asked whether the use of flash cards with pictures was better than the usual ways of learning vocabulary. Again, students of both groups gave positive feedbacks in answering these three items. In other words, the use of Words 716 for accessing flash cards helped to improve learning efficiency, increase learning interests, and reduce cognitive load. This was in agreement with previous research results. The sixth, seventh, and eighth items asked whether integration of stories into flash card learning of vocabulary could help. Students of both groups gave ratings that were slightly higher than the ratings they gave in answering the third, fourth, and fifth items. This suggests that the students agree with the idea of integrating stories into flash card-based vocabulary learning to improve learning efficiency, increase learning interests, and reduce cognitive load. In answering the ninth and tenth items, students generally agreed that Words716 was indeed a good tool that assisted the learning of English vocabulary.

In answering Item No. 11, the students made the following comments and suggestions. One, the stories that were integrated with flash card learning were not too long; also, it helped to improve learning efficiency by being able to directly going into the tests after reading the stories. Two, the integration of stories and pictures with flash cards for vocabulary learning, along with the use of smart phones for accessing Words 716 , not only made learning different from the usual ways of directly memorizing vocabulary but also made it much easier to learn anytime and anywhere; this made vocabulary learning more interesting. Three, the design of Words716 was simple and easy to understand; users were able to almost use the system directly; also, since the interface was nice and elegant, this had helped not to become less interested after using the system for a while. Four, one drawback of the experiment was that the content of learning did not change throughout the experiment; this had resulted in boredom for at least some of the students. Five, it may help vocabulary learning by adding KK (Kenyon and Knott) phonetics and perhaps even pre-recorded pronunciations to the vocabulary being learned. Six, the use of smart phones should include iPhones and not just Android-based smart phones. These comments and suggestions will be taken into careful considerations when revising Words716 in the future. 
Table 5. Questionnaire results for the usage of Words716

\begin{tabular}{|c|l|c|c|}
\hline $\begin{array}{c}\text { Item } \\
\text { number }\end{array}$ & \multicolumn{1}{|c|}{ Item } & Experimental & Control \\
\hline 1 & $\begin{array}{l}\text { Words716 allows me to use my spare time to learn English vocab- } \\
\text { ulary. }\end{array}$ & 3.92308 & 3.80769 \\
\hline 2 & $\begin{array}{l}\text { It is very convenient for me to use smart phones to access } \\
\text { Words716 and do vocabulary learning. }\end{array}$ & 3.87179 & 3.84615 \\
\hline 3 & $\begin{array}{l}\text { Words716 uses flash cards with pictures to help me learn English } \\
\text { vocabulary. This is better than the usual method of direct memo- } \\
\text { rizing vocabulary. }\end{array}$ & 3.94872 & 3.73077 \\
\hline 4 & $\begin{array}{l}\text { I am more interested in using the digitized flash cards provided by } \\
\text { Words716 to learn English vocabulary. }\end{array}$ & 3.92308 & 3.84615 \\
\hline 5 & $\begin{array}{l}\text { When I used flash cards provided by Words716 to learn English } \\
\text { vocabulary, I felt my burden (in doing it) was lighter than usual. }\end{array}$ & 3.94872 & 3.88462 \\
\hline 6 & $\begin{array}{l}\text { When learning English vocabulary, it is more helpful to me if the } \\
\text { words to be learned are part of a story and I can read the story at } \\
\text { will. }\end{array}$ & 4.12821 & 3.96154 \\
\hline 7 & $\begin{array}{l}\text { When learning English vocabulary, I will be more interested in } \\
\text { learning the vocabulary if the words to be learned are part of a story } \\
\text { and I can read the story at will. }\end{array}$ & 4.20513 & 4.11538 \\
\hline 8 & $\begin{array}{l}\text { When learning English vocabulary, I feel my burden is lighter if the } \\
\text { words to be learned are part of a story and I read the story at will. }\end{array}$ & 4.15385 & 4.07692 \\
\hline 9 & $\begin{array}{l}\text { I think Words716 is a good tool that assists me in vocabulary } \\
\text { learning. }\end{array}$ & 4.02564 & 4 \\
\hline 10 & $\begin{array}{l}\text { From 1 to 10 (1 means very bad, 10 means very good), how would } \\
\text { you rate Words716 as a tool that assists you in vocabulary learning? }\end{array}$ & 7.82051 & 7.69230 \\
\hline \begin{tabular}{l} 
Do you have any thoughts and suggestions regarding Words716? \\
\hline
\end{tabular} & & \\
\hline
\end{tabular}

\section{$5 \quad$ Conclusion and Future Work}

As the technology of Internet and mobile devices rapidly develop in the recent years, more and more courses are equipped with learning assisted systems that run on mobile devices. Therefore, students are no longer confined to desks and classrooms (or even desktop computers). They are able to learn anytime and anywhere with the use of suitable mobile devices.

Even though mobile learning helps students to learn, there is still the question of what teaching strategies should be used in order to increase students' learning interests and motivation. This is still an issue that is being actively researched upon. In the current research, a flash card-based vocabulary learning system named Words716 was developed for mobile devices. It integrated stories and pictures into flash card learning of vocabulary. Words716 has a simple interface and makes use of portability and convenience offered by mobile devices. Therefore, students were able to almost use it directly, without having to go through a long and tedious trial and error process. To overcome the shortcomings of mobile learning such as screen-too-small and input-inconvenient pointed out by Shen et al. [15], Words716 was designed so that students only needed to touch the screen in order to do vocabulary learning.

From the experiment conducted in this research, it was found that anxiety in learning English decreased significantly for both the control group and the experimental group; 
however, integration of stories with flash card-based vocabulary learning helped members of the experimental group to perform better in two aspects: learning motivation and learning achievement. In other words, the strategy of integrating stories and pictures with flash card-based vocabulary learning is better than "pure" flash card-based vocabulary learning.

There are improvements to be made for future versions of Words716. For example, iOS-based smart phones should be supported; there should be constant updates to the stories; the number of words to be learned should increase; KK phonetic symbols or even oral pronunciations should be added to the digitized flash cards. These improvements can all help Words 716 to become more appealing to students so as to keep them interested in using the system. In order that the students do not lower their expectations of or even become bored in using Words716, the first priority will be to add constant updates to the stories provided by the system and increase vocabulary to be learned. Once the students are able to maintain their interests and expectations of the system, it will be more likely that they use the system for a prolonged period of time and make better learning achievements.

\section{$6 \quad$ References}

[1] Cui, Y., \& Bull, S. (2005). Context and learner modeling for the mobile foreign language learner. System, 33, 353-367. https://doi.org/10.1016/j.system.2004.12.008

[2] Emrah, B. B., Omur, A. (2010). A Comparison of Undergraduate Students' English Vocabulary Learning: Using Mobile Phones and Flash Cards. Turkish Online Journal of Educational Technology - TOJET, 9(3), 1-7.

[3] Fauziati, E. (2005). Teaching of English as a foreign language (TEFL). Surakarta: Muhammadiyah University Press.

[4] Gromik, N.A. (2011). Cell phone video recording feature as a language learning tool: A case study. Computers \& Education, 58(1), 223-230. https://doi.org/10.1016/j.compedu.2011. $\underline{06.013}$

[5] Horwitz, E., Horwitz, M., \& Cope, J. (1986). Foreign language classroom anxiety. The Modern Language Journal, 70, 125-132. https://doi.org/10.1111/j.1540-4781.1986.tb 05256.x

[6] Huang L. (2010). Using GPS to design narrative-centered environments for guided discovery learning: "Façade" - a case study of a nonlinear story. Procedia Social and Behavioral Sciences 2, 4032-4037. https://doi.org/10.1016/j.sbspro.2010.03.636

[7] Hwang, G. J., Wu, C. H., Tseng, J. C. R., Huang, I. (2011). Development of a ubiquitous learning platform based on a real-time help-seeking mechanism. British Journal of Educational Technology, 42(6), 992-1002. https://doi.org/10.1111/j.1467-8535.2010.01123.x

[8] Laufer, B. (1997). The lexical plight in second language reading. Cambridge: Cambridge University Press.

[9] McGraw, I., Yoshimoto, B., Seneff, S. (2009). Speech-enabled card games for incidental vocabulary acquisition in a foreign language. Speech Communication, 51(10), 1006-1023. https://doi.org/10.1016/j.specom.2009.04.011

[10] Mitchell, K. \& Nicholas J. P. R. (2005). uLearn: Facilitating Ubiquitous Learning through Camera Equipped Mobile Phones. wmte, IEEE International Workshop on Wireless and Mobile Technologies in Education (WMTE'05), 2005, 274-281. https://doi.org/10.1109/ wmte.2005.69 
[11] Nation, I. S. P., (2001). Learning Vocabulary in Another Language. Cambridge University Press.

[12] Oxford, R., Crookall, D., 1990. Vocabulary learning: a critical analysis of techniques. TESL Canada Journal 7, 9-30. https://doi.org/10.18806/tesl.v7i2.566

[13] Pintrich, P., Smith, D., Garcia, T. \& McKeachie, W. (1991). A manual for the use of the motivated strategies for learning questionnaire (MSLQ). National Center for Research to Improve Post-secondary Teaching and Learning.

[14] Segler, T., Pain, H., \& Sorace, A. (2002) - Second language vocabulary acquisition and learning the strategies in ICALL environments. Computer Assisted Language Learning, 15(4), 409-422. https://doi.org/10.1076/call.15.4.409.8272

[15] Shen, R; Wang, M; Gao, W; Novak, D; Tang, L (2009). Mobile Learning in a Large Blended Computer Science Classroom: System Function, Pedagogies, and Their Impact on Learning. IEEE Transactions on Education, 52(4), 538-546. https://doi.org/10.1109/te.2008.930794

[16] Shih, J. L., Chuang, C. W., \& Hwang, G. J. (2010). An Inquiry-based Mobile Learning Approach to Enhancing Social Science Learning Effectiveness. Educational Technology \& Society, 13 (4), 50-62.

[17] Wilkins, D. A. (1972). Journal of the International Phonetic Association, 2(1), b1-b4.

[18] Zimmerman, C.B. (1998). Historical trends in second language vocabulary instruction. In J. Coady and T. Huckin (Eds.), second language vocabulary acquisition: A rationale for pedagogy, Cambridge: Cambridge University Press, 5-19. https://doi.org/10.1177/0033688298 $\underline{02900109}$

\section{$7 \quad$ Authors}

Chien-Hung Lai is an assistant professor in the Department of Electronic Engineering, Chung Yuan Christian University, Taiwan. His research interests include computer aided education.

Bin-Shyan Jong, Yen-Teh Hsia, and Tsong-Wuu Lin are with Chung Yuan Christian University, Taiwan.

Article submitted 2019-09-22. Resubmitted 2019-12-06. Final acceptance 2019-12-08. Final version published as submitted by the authors. 